\title{
Indonesian Biology Teachers' Perceptions about Socio-Scientific Issue-Based Biology Instruction
}

\author{
Agung W. Subiantoro| ORCID: 0000-0002-0576-6457 \\ Corresponding author, \\ Department of Biology Education, Yogyakarta State University, \\ Sleman, Di Yogyakarta, 55281, Indonesia \\ agung_wijaya@uny.ac.id \\ David Treagust | ORCID: 0000-0001-5340-0970 \\ School of Education, Curtin University, Perth, WA 6845, Australia \\ D.Treagust@curtin.edu.au \\ Kok-Sing Tang | ORCID: 0000-0002-2764-539X \\ School of Education, Curtin University, Perth, WA 6845, Australia \\ kok-sing.tang@curtin.edu.au
}

Received: 30 June 2021 | Revised: 24 October 2021 | Accepted: 29 October 2021

\begin{abstract}
Promoting socio-scientific issue (ssi)-based instruction in Indonesian science classrooms requires competent science teachers. To understand teachers' perceptions about the implementation of ssi-based instruction, a case study involving four biology teachers engaged in a teacher professional development program was conducted. The program consisted of four phases: reflection on teachers' prior teaching experience and background knowledge, 3-day ssi-based teaching workshop, collaborative development and implementation of ssi-based learning in biology, and post-implementation reflections by teachers. Teachers' perceptions were gathered via interviews and written reflections, which were analyzed qualitatively with an explanation building mode approach. Findings indicated a positive development along four dimensions: knowledge about ssis and scientific literacy, the necessity of including ssis in science instruction, situational factors related to addressing ssis in class, and teachers' attitude towards teaching ssis. Further research needs to be conducted in Indonesian contexts to be able to extend the ssi teacher professional development program to different regions.

(C) SUbIANTORO, TREAGUST AND TANG, 2021 | DOI:10.1163/23641177-BJA10032

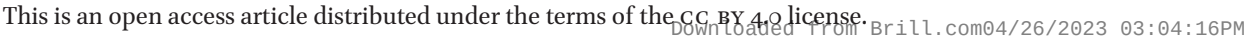




\section{Keywords}

socio-scientific issues - teacher professional development - teachers' perceptions

\section{Introduction}

During the last decades, socio-scientific issue (ssi)-based education has been an influential movement for global science education research and practice. ssis are open-ended problems where complexly structured issues, science knowledge and ways of thinking about it are interrelated with social perspectives, and there is a potential of bringing out any dilemmas that exist in society (Sadler, 2011; Sadler \& Dawson, 2012; Zeidler, 2013; Zeidler, Herman, Ruzek, Linder, \& Lin, 2013). People may have distinct opinions based on their understanding of science, their values, and ethical considerations, which all influence them in negotiating issues and in making decisions (Zeidler, Sadler, Simmons, \& Howes, 2005). Issues such as genetically modified organisms (GMOs), global warming and climate change, and nuclear energy have been recognized and implemented in science education research and practices globally to contextualize science problems in the classroom and investigate the development of students' scientific knowledge and reasoning skills and their levels of argumentation (Feierabend \& Eilks, 2010; Chowning, Griswold, Kovarik, \& Collins, 2012; Lenz \& Willcox, 2012; Ottander \& Ekborg, 2012; Dawson \& Venville, 2013).

While it has been implemented in a wide range of contexts in many countries, ssi-based education is still in the growing development phase in science education practice in Indonesia, with a limited number of studies having been carried out (e.g., Herlanti, Rustaman, Rohman, \& Fitriani, 2012; Nida, Mustikasari, \& Eilks, 2020). Science learning in secondary schools in Indonesia is taught mainly as the subjects of physics, chemistry and biology. Particularly for biology education, one of the essential curriculum goals is probing and selecting relevant evidence and information to solve daily life problems: This focus is likely to be close to scientific literacy. In this regard, the Indonesian national curriculum provides opportunities for each school to develop and fulfill its instructional needs based on the school's physical and socio-cultural background to attain the curriculum goals. This situation implies that Indonesian biology teachers need to have a clear consideration of how to introduce a program of well-developed contextual learning to present an ideal learning environment and meet the recommended instructional objectives, especially scientific literacy.

To make learning meaningful, some studies have pointed out the importance of the social dimension as an essential component of science education 
practice to ensure scientific literacy (Tal \& Kedmi, 20o6). In this context, scientific literacy implies that an individual student must develop the ability to critically evaluate and apply information, make an appropriate decision, and participate in debates or discussions about science-related problems in a live environment such as a classroom (Arroio, 2010; Hofstein et al., 2011; Zeidler \& Nichols, 20o9; Zeidler, Sadler, Simmons, \& Howes, 2005). Holbrook and Rannikmae (2009) suggested that teaching with ssis is necessary for students to be involved in contemporary science education practice so that their scientific literacy becomes stronger and broader.

Promoting ssi-based learning as a useful strategy for scientific literacy in biology education in Indonesia requires well-prepared biology teachers who can be encouraged to implement ssis and be aware of their important role in biology learning (Ekborg, Ottander, Silfver, \& Simon, 2013; Forbes \& Davis, 2008). However, since this strategy has been less recognized in science education practice in Indonesia, attempting its development requires addressing how Indonesian science teachers perceive their readiness to teach in this way (Nida, Rahayu, \& Eilks, 2020; Nida, Mustikasari, \& Eilks, 2020).

Many research studies have revealed factors that may either support or impede teachers' implementing ssis (Barret \& Nieswandt, 2010; Lee, Abd-El-Khalick, \& Choi, 2006; Kilinc et al., 2014; Wolfensberger et al., 2010). Moreover, the importance of investigating science teachers' experiences with and perceptions of ssi implementation in science classrooms has been promoted by several studies. Research by Reis and Galvao (2004), for instance, revealed a contradictory view held by teachers regarding ssi-based instruction. On the one hand, teachers perceived ssis to have a strong potential for scientific literacy-oriented achievement. On the other hand, ssi learning may inhibit the teacher's responsibility to assist students to successfully pass their final examinations when ssis are not part of the examined curriculum. The goal of concept attainment, which curricula tend to emphasize, and the time required are issues that need to be considered when including ssis in the curriculum. Furthermore, when dealing with factors that may impede teacher readiness to teach ssis, it is important for teachers to reflect on their own views when confronted with controversial issues and how to teach these issues to students. Kara (2012) suggested that to assist teachers in their preparation for implementing ssi-based learning, it is beneficial to understand their beliefs about their teaching practices with ssis and factors that relate to teachers' awareness of adopting ssi teaching.

In research on teachers' insights about their own epistemic beliefs and awareness of those factors that may influence their perceptions of ssi-based teaching, Lee, Abd-El-Khalick, and Choi (2006) identified factors that impeded teachers' teaching practices using ssis. These factors were teachers' epistemic 
beliefs about Ssis, concerns about their own personal values and the impact those may have on students' views, the lack of pertinent learning material and time to prepare it, and difficulties in selecting teaching strategies in terms of moral and ethical dimensions. Indeed, the influence of teachers' personal values and concerns about innovation in their practice of teaching has been considered in science education reform because teachers "are teaching whatever they feel is important without much contact with reform ideas" (Lee \& Witz, 2009, p. 932).

While calls for professional development to improve teachers' readiness to adopt ssi teaching have been issued (Gray \& Bryce, 2006; Lee \& Witz, 2009), research focused on designing and implementing a particular teacher professional development for SSI teaching has still been rare. In regard to this, van den Akker (1988) demonstrated that teachers' understanding and awareness of the meaning of ssi-based instruction as an innovation in their daily roles in science teaching practice strongly influenced how they were be able to implement it and accordingly determine the degree of its effectiveness. Supporting this view, Albe et al. (2014) also emphasized that because science teachers play an important role in any science instruction innovation, an investigation of teachers' perceptions and awareness of innovation need to be investigated.

Promoting innovation in science education, particularly related to curriculum and its implementation, certainly requires teacher preparation because each teacher plays an important role in interpreting and putting the innovation into teaching practice (Bakkenes, Vermunt, \& Wubbels, 2010; Konings, Brand-Gruwel, \& van Merrienboer, 2007; Peers, Diezmann, \& Watters, 2003). Therefore, teacher professional learning or professional development has been recognized as a useful medium to enable this preparation (Borko, 2004; Davis, 2003; Pinto, 2005). Guskey (2002) asserted that well-designed teacher professional learning aims at helping teachers review and transform their beliefs, attitudes, and perceptions. Bitan-Friedlander, Dreyfus, and Milgrom (2004) suggested that successful teacher professional development for introducing innovation occurs when teachers are motivated and can implement innovations in their classes and make necessary adaptations for future needs.

\section{Research Framework and Objectives}

Science teachers play an important role in SsI implementation with respect to their management skills in student discussion, their knowledge of nature of science (NoS) and its relation to non-scientific elements (socio-political or values aspects) of science knowledge, their conceptions about science teaching, and evaluation approaches, particularly for evaluating ssi discussions (Albe 
et al., 2014). Understanding how Indonesian biology teachers perceive themselves to be aware of and ready for practicing ssi-based teaching in school science, must first be considered as a means of working on promoting ssIbased learning.

The research reported in this article, which is a part of a larger study (Subiantoro, 2017), focused on the "reflection-in-action" framework (Simon \& Campbell, 2012) because it involved a thinking activity about an event or occasion (i.e., teacher professional learning program) in which teachers are involved. Further, Konings et al. (2007) asserted that the participatory design is a stronger approach rather than only informing the targeted teachers about the innovation. This approach provides an occasion for teachers to participate in the professional learning program with an analysis of their needs and possibilities and generates the framework and management and arranges the implementation of the innovation. Consequently, this research was driven by the framework that included (1) reflection activities, either written or verbally expressed, that play an essential part in the teacher professional learning program, and (2) the program that was designed in phases for understanding participant prior knowledge and beliefs, introducing the ssi-based learning concept, and preparing an ssi teaching practice and conducting it in a biology classroom.

This research focused on promoting ssi-based instruction in Indonesian schools through a specially designed professional development learning program and examined how four biology teachers perceived their teaching roles. The research question that led this research was: What perceptions do Indonesian biology teachers develop of an ssi teaching practice developed by a teacher professional learning program?

\section{Methodology}

\subsection{Research Design and Participants}

This research was designed to examine how ssi-based instruction is perceived by Indonesian biology teachers in the context of their classrooms. This research aimed at investigating contemporary phenomena that are likely to occur when an innovation, in this case, ssi-based instruction, is implemented. Therefore, following Yin's (1994) definition, this research could be defined as case-study research because it was an empirical inquiry that investigated a contemporary phenomenon within its real-life context consisting of a program or a social group (i.e., biology teachers and their classrooms) to understand a problem of practice (Merriam, 1990). The "case" in this research is defined as four biology 
teachers' perceptions about ssi-based teaching practice in the context of teacher professional development.

Four biology teachers with various teaching experience voluntarily participated in this research in the frame of a teacher professional development program offered by the researchers. The teachers had been teaching in different schools from different areas that represent distinct socio-economic backgrounds. However, all teachers were from the same region of the Special Province of Yogyakarta, Indonesia. The first author (hereafter referred to as "the researcher") had been actively involved in teacher professional development programs and activities involving collaboration between the Biology Teachers Association and teacher training education institutions. Based on this academic relationship, the researcher introduced and offered the ssi professional development program through the Association to any biology teacher who was interested in participating. In this way, the four biology teachers expressed interest and joined the program. Due to ethical considerations, the names of the participants in this report are pseudonyms.

Mr Budi, who had been teaching for 17 years, was a biology teacher in a senior high school in the Bantul district. In the same district as Mr Budi, Ms Nur had been teaching for 10 years. From the city of Yogyakarta, Ms Dwi had been teaching for 13 years in a senior high school. These three teachers were officially employed by the Department of Education. In comparison to these three teachers, Ms Aisi was a less experienced teacher who was not officially employed by the Department. However, for this research, Ms Aisi was permitted to teach one Grade 10 class in the same school with Ms Dwi and Ms Nur. In this research, each teacher taught one class each with various numbers of students that had been suggested and approved by the school principal.

\subsection{Data Collection}

As this research was designed in the frame of a teacher professional development program on ssi-based teaching and learning, the data collection for this research was embedded during the program mainly through interviews and supported by written expressions from their reflective journals. The ssis introduced in the lesson were breastfeeding vs. formula milk (Mr Budi), mobile phones and society (Ms Dwi and Ms Nur), motorcycles driven by students (Ms Aisi), and hotel development and water sustainability (Ms Aisi). The program and data collection were carried out in four phases as follows.

3.2.1 Phase 1: Prior Teaching Experience and Background Knowledge The first phase of this research was designed to explore teachers' teaching experiences and their background knowledge regarding ssis. Through a reflection 
sheet followed up by semi-structured interviews, the participants were asked to describe their experiences teaching a certain biology topic and the instructional strategy that was employed in teaching the topic. They were also asked about their prior knowledge of the ssi-related topic in biology and whether they had experience in teaching it and about scientific literacy and its relevance to biology teaching and learning. Following the reflection activity, the researcher provided a plan for the workshop on ssi-based instruction and discussed with each of the participants the time that would be required, a brief preview of what they would do, and the schedule for implementation and observations.

\subsubsection{Phase 2: 3-Day Workshop on SsI-Based Teaching}

The second phase consisted of 3 days of professional development workshops. The main objectives of the workshops were to provide the basic theoretical framework of ssis and practical teaching aspects for the teachers. With this information, the teachers were able to develop their knowledge and basic skills of ssi-based instruction and consider various ways of implementing it in their classroom. The content discussed in the workshops included the characteristics and objectives of ssi-based learning, instances of ssis in Indonesian contexts, and the basic framework of ssi-based strategy. The written reflective journals were collected from each participant to examine their understanding of ssis and scientific literacy in biology education and the ssi-based teaching strategy and its implementation in the biology classroom. An interview was also conducted to review what each participant had written and to discuss their thoughts about factors that may support or impede ssi-based teaching that need to be considered and general perceptions of ssi teaching preparations.

\subsubsection{Phase 3: Collaborative Development and Implementation}

Following the workshops, the third phase involved collaboration between the researcher and the four biology teachers to develop the ssi-based teaching materials. Concerning ethical issues, consideration was given to compliance with the school academic timeframe and curriculum needs. It should be noted that in this research, because one common timeline for implementing the lesson program could not be determined, the teachers chose their own timeline. This meant that the teachers had their own schedules for implementing ssi-based instruction in their biology classes. The researcher and teachers discussed the potential topics that were available for implementation in the intended time frame that was suggested by each participant. Assisted by the researcher, lesson plans for each issue were written by the individual teachers who implemented the ssi-based teaching in their biology classroom based on the arranged schedules. 


\subsubsection{Phase 4: Post-Implementation Teachers' Reflections}

As the end of the teacher professional learning program, after teaching their classes, the fourth phase comprised in-depth interviews with all teacherparticipants to understand their perceptions after implementing the ssi-based teaching practice. A review of teacher knowledge on ssi teaching, the advantages and challenges that occurred during the implementation, and views of possibilities for further development were some aspects that were explored. The interviews were carried out in Bahasa Indonesia, voice recorded, and acknowledged by the participants.

\section{Data Analysis}

The main data source for this research was interviews concerning biology teacher participants' views about their ssi teaching practice before and after participating in the professional development program. These data were collected in Bahasa Indonesia and then translated into English. The translation results then were reviewed by a language expert in both English and Bahasa Indonesia to gain a valid conformity of the translation. Following this translation stage, transcribing the data was undertaken for further analysis.

The basic framework of analysis that underpinned this research was an explanation building mode, including defining the unit of analysis (i.e., biology teachers' statements), organizing the data chronologically, finding the pattern of the unit analysis, and interpreting the pattern on defined dimensions or propositions based on the literature (Merriam, 199o; Miles \& Huberman, 1994). To contextualize the research, the dimensions or propositions used for the interpretation were modified from the existing literature (Lee, Abd-El-Khalick, \& Choi, 2006). The literature describes three important dimensions of teachers' perceptions: the necessity of including ssis in science instruction, situational factors related to addressing ssis in class, and teachers' attitudes regarding ssis. However, as this research considered the importance of teacher knowledge of ssis, this additional dimension was also considered in the framework. Thus, four dimensions of teachers' perceptions were used as the propositions for the general strategy of the analysis.

In the first stage of analysis, the transcribed text of interview data was carefully read by the researcher to seek clues of expression that may reflect biology teachers' perceptions of each of the four dimensions: knowledge of ssis and scientific literacy, necessity of ssis in the biology classroom, factors influencing ssis, and teachers' attitude towards teaching ssis. The data from this first stage were then classified according to each dimension and confirmed with the basic definition based on the literature. Following this classification and 
confirmation, samples of excerpts were then added to highlight the teachers' interpretations of their teaching of the ssis. This first version of interpretation was then discussed by the researchers to gain a conceptual agreement and to determine a comprehensive picture of the results. Hence, after a couple of these discussions, the interpretation was finalized and re-written for this report. To establish data validation and reliability, this research applied trustworthiness and authenticity of the data considerations through member checking by which participants were asked to check the validity of the data translations and to provide any review of the interpretations constructed by the researchers (Creswell \& Miller, 2000).

\section{$5 \quad$ Results}

The findings from this study are reported according to four key dimensions of perceptions: (1) teachers' knowledge of ssis and scientific literacy, (2) the necessity of ssis in the biology classroom, (3) factors that influence ssi teaching and learning, and (4) teachers' attitudes towards teaching ssi. For each dimension of perceptions, data on teachers' perceptions of ssi teaching practice are described based on pre and post implementation of ssi teaching.

\subsection{Dimension 1: Teachers' Knowledge of ssi and Scientific Literacy}

Based on their prior reflections through interviews, before the workshop, teachers may have had distinct prior knowledge about ssis and scientific literacy. The following excerpts from two teachers support this finding.

\section{Episode 1}

\begin{tabular}{|c|c|}
\hline searcher & Based on your experience, what do you know about ssis? \\
\hline Ms Aisi & $\begin{array}{l}\text { They are conceptual webs of biological knowledge and involve } \\
\text { social perspectives, }\end{array}$ \\
\hline Researcher & $\begin{array}{l}\text { And what about scientific literacy? What do you think about it } \\
\text { related to ssis? }\end{array}$ \\
\hline Ms Aisi & $\begin{array}{l}\text { Scientific literacy means having knowledge related to, being able to } \\
\text { find information, and communicating these to resolve an ssi. }\end{array}$ \\
\hline Researcher & What needs to be communicated? \\
\hline Ms Aisi & $\begin{array}{l}\text { Information or facts that are relevant to the issue and relevant to } \\
\text { biological concepts }\end{array}$ \\
\hline
\end{tabular}




\section{Episode 2}

Researcher

Mr Budi

Researcher

Mr Budi
What can you tell me about ssis? What do you know about them? Like I wrote in my [reflection] sheet, ssis are problems in society and related to science or biology. And what do you know about scientific literacy? It is a way to learn science. That is what I know so far.

Ms Aisi's words indicate that she viewed biological knowledge and social perspectives as two main aspects of ssis. She also added that the related knowledge that may be functional in dealing with these issues is supposed to be more complex than a simple concept. Regarding her understanding of scientific literacy, she stated that the three main abilities that comprise scientific literacy skills are having appropriate knowledge, seeking relevant information, and communicating a clear understanding to resolve the issue. On the other hand, Mr Budi described ssis as issues that exist in society and are interrelated to science or biological knowledge.

When compared to Ms Aisi's earlier statement, this description seems simpler and less elaborated. Regarding scientific literacy, Mr Budi states that being scientifically literate is a way that may lead students to learn science, in his case, biology. The perceptions expressed by these two teachers suggest that a lack of experience with ss I-based instruction considerably influences teachers to figure out their own understanding about ssis and the need for scientific literacy based on their prior understanding.

Based on interviews after the implementation of ss I teaching, the following excerpts are the teachers' answers regarding the question: "We tried to implement Ss I-based teaching [with a selected issue]. Do you think it was representing an ssi?" and "If so, what is your understanding about scientific literacy?"

\section{Episode 3: Mr Budi}

I think it was. As there was a controversy between biological knowledge and social aspects related to breastfeeding and formula milk. This leads students to make a decision [about it]. (excerpt 1)

What I can see is that yesterday students reviewed some information relevant to the issue from different perspectives in order to make a decision about the issue and deliver their reasoning to the class. I think this is scientific literacy. (excerpt 2) 


\section{Episode 4: Ms Aisi}

What I can say about ssis and scientific literacy is that these are more complex than I previously thought. A main point of ssis is that there are controversies between science and the social dimension. (excerpt 1)

Scientific literacy is a skill necessary to deal with ssis. (excerpt 2)

Reviewing the views after ss I teaching practice stated by both teachers revealed a trend in the change in their perceptions of ssis and scientific literacy. Both Mr Budi and Ms Aisi had likely found a key point in ss I knowledge as they mentioned "a controversy between science and the social dimension." However, Mr Budi had an additional understanding, as he asserted the decision-making aspect in his statement on ssis. Regarding scientific literacy understanding, while Ms Aisi simply stated that scientific literacy is a skill necessary to deal with ssis, Mr Budi involved selecting relevant information, making a decision, and reasoning in stating his view of the meaning of scientific literacy. To sum up, there were different degrees in the extent to which additional knowledge about ssis and scientific literacy were gained by teachers after ssi teaching practice.

\subsection{Dimension 2: The Necessity of ssis in Biology Classrooms}

According to the interview findings before implementing the ssi teaching, the four teachers perceived the necessity of the ssi lessons from the point of view of its educational advantages, as represented by the following excerpts:

\section{Episode 5}

Researcher You mentioned before that you are interested in implementing ssis in your biology classroom. What makes you interested?

Ms Dwi Well, based on my limited knowledge of ssis that we discussed before, I think they [ssis] will help my students to understand biological concepts and arouse their empathy or humanistic values. They may also be helpful in regenerating students' awareness about their environment. Through ssis, perhaps my student could review social values in their daily life. 


\section{Episode 6}

Researcher

Ms Aisi

Researcher

Ms Aisi
How do you think that ssis are different from other instructional strategies?

I think ss Is may help encourage students to get more knowledge. Only biological knowledge?

No, they also may help students to have social considerations beyond their understanding the biology topic being discussed.

Although it was not explicitly stated as the necessity of the ssi lesson, the teachers' words in the above excerpts reflected the way they viewed the importance of ssis in their biology classrooms. From Ms Dwi's statements in Episode 5, for example, she asserted that the potential role of an Ssi was to help her students gain biology knowledge and social considerations related to the issue and be aware of their reasoning. The dimension of knowledge and social considerations also emerged in Ms Aisi's words to support her view on the advantage of ssi lessons.

Reviewing teachers' reflections after the ssi teaching practice shows that their perceptions appeared more profound regarding the advantages of ssi-based learning, particularly in terms of an increased level of engagement of their students. These were reflected by the excerpts below.

\section{Episode 7}

Researcher

Ms Aisi

\section{Episode 8}

Researcher

So, did you see something interesting about ss I learning in your biology classroom?

Ms Dwi son for your biology classroom?

Well, the first thing I could see from my class is that students was their first experience in having a role-play discussion involving an SsI. They perceived it was different. And I could see some students were trying to do critical thinking.

I saw that my students were more attentive [in the lesson]. It
Can you share your experience regarding the function of an SsI leslooked more engaged in ssi learning, and this is supported by some students when I asked their opinion about their lesson. They said it seemed like it was because they felt free, different from their common learning pattern, as maybe they feel bored with my way of teaching as well. 
Researcher What about student achievement?

Ms Dwi Students really seemed to feel encouraged to express their social consideration and responsibility, like L [a name of student] who wanted to participate in community service for a campaign about the issue. Overall, I felt that my students became more aware about the social dimension of the topic being learned.

The above excerpts show that both teachers perceived a few key aspects of ss I lesson advantages in relation to student activities. One of them, as asserted by Ms Aisi, was the encouragement they received from the group activities when the students critically shared information and opinions. Similarly, Ms Dwi also focused on her student engagement in ssi lessons. She noticed that in ssi learning, her students were "becoming more aware about the social dimension of the topic being learned." Therefore, comparing their words before the implementation of ssi teaching shows the extent to which the teachers gained a wider point of view of considering ss I learning advantages, or their necessity, for their biology classrooms.

\subsection{Dimension 3: Factors Influencing ssi Teaching}

The findings show that all teachers stated that the two main factors that need to be considered are defining the issues that have evolved in society that are relevant to the biology topic being discussed and identifying relevant scientific information about the issue. Following these topic-related factors, teachers became aware of pedagogical aspects as important factors, including an appropriate teaching approach or model (Mr Budi and Ms Dwi), student characteristics (Ms Dwi and Ms Nur), and teacher skills and creativity (Ms Aisi and Ms Dwi). The words expressed by Ms Dwi below represent the findings:

\section{Episode 9}

Researcher So, do you think you are interested in teaching with ssi?

Ms Dwi

I am interested, but, honestly, not really ready. As I am do not fully understand and have no clear idea on how to teach with ssis. I think I need more reference about theoretical aspects and practical guidance in ssi teaching. I also am concerned about how to fit ssis into our curriculum needs.

Researcher What about other factors related to, for example, teaching preparation?

Ms Dwi Perhaps the learning resources. I do not know how appropriate it is, but usually I allow my students to find information through the internet. 
Having experience in SsI teaching practice may lead teachers to take the factors into account more deeply. Another perspective occurred from Ms Dwi's experience, as she explained:

\section{Episode 10}

Researcher Do you think ss I teaching that you have implemented is in alignment with our curriculum needs?

Ms Dwi To some extent. But, as you know, our curriculum is mainly oriented toward national exams, and the teacher must teach all topics or concepts required. To be honest, I am actually interested in ssi teaching, as it is relevant to the science-technology-society approach. But we have limited time as we must consider the school exam.

Researcher What is your regular teaching pattern?

Ms Dwi It depends on the topic. However, according to my colleagues here in the school, a teacher could not be called a teacher unless someone is able to teach by lecturing.

Researcher Does this teaching culture influence the way students learn?

Ms Dwi Definitely. The teacher is delivering the concepts and perhaps the student receives the knowledge. They [students] are accustomed to this pattern. They have a book, but if they are not encouraged to read, they will not do it. They prefer to be taught by lecturing.

Ms Dwi's words revealed that she was facing a dilemma, because while she was encouraged to teach about ssi, she was also aware of the demands of the final examination. This situation may become more challenging because there is an extent to which the teaching culture in her school influences her perceptions of the way she needs to choose what and how to teach in her biology classes. Thus, this school orientation and culture represents factors that may also influence ssi teaching practice.

\subsection{Dimension 4: Teacher Attitude}

The interviews with each of the teachers generally revealed that they face a psychological dilemma faced in deciding whether they intend to implement ss I teaching. Mr Budi's and Ms Nur's statements below may represent this finding.

\section{Episode 11}

Researcher

After participating in the workshop, do you think you are interested in SSIs? 
Mr Budi I am interested. Based on some models of instruction that I already know, these [ssis] are something new for me. I see that they could motivate students to learn comprehensively, not textually.

Researcher What do you need to do to prepare for ssi-based instruction?

Mr Budi I strongly need a guide, an example of ss I teaching materials, and a real example of how to implement ssi-based instruction.

Researcher What challenge(s) do you think will occur?

Mr Budi Students' heterogeneity and my teaching habit, which is teacher centered. With the ssi model, it would be challenging to find a way to encourage students to adopt better thinking skills about the issue being discussed, whereas the most common duty in my teaching is explaining [the topic], giving questions, and possibly providing a hands-on activity about the topic. In other words, the most important problem that ordinarily emerges is how to change or innovate teaching and learning methods in the class to be more student centered.

\section{Episode 12}

Researcher

Ms Nur

Researcher

Ms Nur

Researcher

Ms Nur

Researcher

Ms Nur
How do you understand ssis?

I had heard about them [ssis] before. But since we teach biology in a curriculum-oriented way, we just follow what is in the curriculum. To date, I never learned more.

In your view, what does ssi teaching look like?

We view an issue in our life and environment that is current in our society. However, if a teacher wants to teach such an issue, the teacher needs to understand it first and its relation to relevant biological concepts.

Do think you are interested to do it [ssi teaching] in your biology class?

Well, it is interesting, actually. But, at this time, I am not so sure if I can.

Why?

The fact that I do not have experience with and appropriate knowledge of it. But I am interested.

The above excerpts show there is likely a mental conflict that challenges the teachers regarding their beliefs in implementing ssi teaching practice. While a lack of experience with and knowledge about ssi lessons made them unsure whether they were ready to take on a role in ssi teaching, after looking at the potential advantages of ssi instruction perceived after the workshop, 
they became more interested in doing ssi teaching. However, experiencing ssi teaching may lead to a different degree of change in the teachers' beliefs regarding ssi teaching practice, as reflected by the following excerpts.

\section{Episode 13}

Researcher After practicing ssi teaching, what are the difficulties you think you would face?

Mr Budi How to ensure that the context of the issue conforms with the topic in the syllabus, or our curriculum, and its relevance to social values. It could be hard to do.

Researcher And what about the challenges or threats?

Mr Budi Generally, if students have a good feeling, the lesson plan could be implemented properly. Otherwise, it would be a challenge if students are inactive because we would need to give extra attention, and, unfortunately, it could be an inappropriate use of time.

Researcher But do you think it is possible for further implementation?

Mr Budi Very possible. For instance, in Grade 10, it is possible for the topic of vaccination, or the immune system in Grade 11. For Grade 12, eugenics or evolution are potential topics.

Mr Budi felt that having the context of an ss I conform to the biology curriculum would be a difficulty with ss I teaching implementation. However, it seems that he was ready to deal with this difficulty if he could find a particular biology topic that could potentially be applied in ssi instruction. Moreover, instead of seeing any challenge or threat from himself, Mr Budi was aware that his students' motivation might be an important factor in the effectiveness of sS I learning. However, Mr Budi reflected that he also was motivated and looked forward to ssi teaching again.

Compared to Mr Budi, a similar view was represented in Ms Nur's words, as she stated below:

\section{Episode 14}

Researcher Well, what do you think about ssi teaching after the implementation?

Ms Nur An ssi lesson requires more time in implementation than the method I most commonly use. To implement an ssi lesson requires a great deal of teacher creativity in designing the lesson plans, and the teacher must master the issue and the biological knowledge. 
Researcher Particularly in terms of teaching materials, what needs to be considered?

Ms Nur Looking for up-to-date information and complementary news, so that teacher has a deep understanding about the ssi that will be implemented.

Researcher Do you think you will try to implement ssi teaching again?

Ms Nur sSI is interesting, as I can see it could make students more attentive, and experience something different. Their knowledge might also be better. However, I must make sure that I am really ready with appropriate resources and valid information.

Considering her readiness to implement ssi teaching, Ms Nur was aware of some aspects that might challenge her role in SSI instruction. Creativity in lesson preparation, mastery of the context of the issue and relevant biology knowledge, and well-prepared teaching materials were aspects that she considered and considered when considering implementation of ssi teaching.

Reviewing the teachers' views on their beliefs regarding ss I teaching practice before and after implementation of the ssi instruction revealed that experiencing a real ssi teaching practice led the teachers to acknowledge challenges and advantages of ssi instruction. Thus, this acknowledgement may help develop their self-capacity and beliefs in taking a role in ssi teaching.

\section{Discussion}

The first key finding that was revealed in this research is the fact that before teachers attended the workshop, ssi-based teaching was viewed as a new experience by the participants. Their recognition thus explicitly showed that because they had never learned about ssis before, they lacked the knowledge about Ss Is and scientific literacy orientation in their biology classroom. At this point, the amount of teaching experience had likely nothing to do with the amount of knowledge about ss Is, as stated by Mr Budi and Ms Aisi.

Mr Budi had tried to provide a contextualized problem relevant to the community in his biology classroom; however, he did not consider whether the topic he provided represented an ssi. By asking his students to make an observation of meals traded in the community and possible food preservatives used, Mr Budi intended to attract his students to be involved in the main discourse about the physiology of the digestive system. However, the idea that underpinned his instruction was limited as an attempt to engage students in the topic. On the other hand, there was confusion expressed by Ms Aisi in defining the appropriate meaning of ssis. 
Evidence from the first dimension about the lack of knowledge about ssis and scientific literacy-oriented teaching led to teachers' reflections on the classroom learning environment and most commonly using a teaching approach that was teacher-centered. This may not be separate from how the teachers perceived, interpreted, and actualized the biology curriculum in their classroom instruction. Ms Dwi (Episode \#10) and Ms Nur (Episode \#12) reflected on the situation in which the teacher faced a great challenge in teaching the content-oriented curriculum to ensure student achievement. This situation implies that there were other factors, such as the time required for biology instruction and rearranging the working environment. Therefore, teachers' perceptions of the curriculum orientation, when translated into their teaching duties and into the socio-cultural aspects of the school, had a great influence on their awareness of this teaching innovation (Davis, 2003; Konings, Brand-Gruwel, \& van Merrienboer, 2007; Pinto, 2005).

The circumstances regarding teacher knowledge of ssis, the teaching culture, and the curriculum orientation were modified after the workshop activities (Phase 2 of the research) and during the implementation of the SSI teaching (Phase 3). Introducing ssi-based teaching through a workshop in which participants were involved in discussions about conceptualization of ssis may provide an occasion for participants to consider the potential of the ssis in their biology classroom. Based on the research findings, particularly the insights expressed by Ms Dwi's and Ms Aisi's statements, teachers' perceptions of the necessity of including ssis in biology instruction and the factors influencing SSI teaching practice represent basic insights into the first dimension.

Prior to implementation, the participants' perceptions of the second dimension of the necessity of ssis in general pointed particularly to the intended learning outcomes to be potentially achieved by students, such as obtaining biology knowledge and having social considerations related to the issue. After implementing the ssi teaching with their classes, the participants appeared to develop a deeper insight into the necessity for strengthening the students' understanding of biological concepts, building attitudes within the ssi group activity, and developing critical thinking.

Related to the third dimension of factors that influence ssi teaching, a change of the teachers' perceptions emerged. Before implementing ssi teaching, teachers most likely perceived the factors from an internal point of view, which refers to teacher self-needs, such as how relevant the issue is to the demands of the curriculum, the appropriate teaching approach, or the availability of their teaching skills. However, the advantages of experiencing the classroom environment and seeing the students' achievements, deciding the time requirement, and considering the school community or culture are factors that represent the external points of view that were considered by these 
four teacher participants after practicing ssi teaching in their biology classrooms. These practical aspects of ssi teaching could not have been reflected upon unless the teachers had experienced them (Guskey, 2002).

In this way, the teachers were able to consider the student activities and the class situation. By trying to apply an innovation introduced in the professional learning program, the teachers were able to have a broad overview of the learning environment of their class and evidence of students' achievement and the advantages of promoting a change of beliefs and attitudes. Similarly, Borko (2004) and Bakkenes, Vermunt, and Wubbels (2010) found that classroom practice is a powerful medium for teacher change. When teachers are in a real context for teaching and can reflect on their teaching habit as part of their professional development, change can be effective.

The change of the first dimension of knowledge about ssis, the second dimension about the necessity of ssis in the biology classroom, and the third dimension about factors that influence ssi teaching may drive the change in the fourth dimension of perceptions, namely, teachers' attitudes. Likewise, the three dimensions of the participants' notions mirror the flow of teacher perspective regarding their attitude on ssi teaching. What can be viewed before the ssi teaching practice was that the four teacher-participants saw themselves as not being competent in the practice of ssi teaching due to their lack of knowledge and experience. However, attending the professional development workshop and considering the factors that they encountered during their experience of the classroom implementation led to an increase in their interest in the practice and recognition of the advantages and insights for further implementation. However, as shown in Episode 13 for example, it is clear that the teachers' attitude, with support of the knowledge of ssis, can provide strong confidence and capability for teachers to address ssi-based instruction. In this way, they can provide appropriate classroom environments for the intended purposes (Albe et al., 2014).

\section{7 Conclusion and Implications}

This research was conducted mainly to investigate and understand how biology teachers perceived their experience and knowledge about ssi-based instruction in their biology classrooms based on their participation in a teacher professional development. The data gathered generally indicate that teachers' knowledge and experience showed a positive trend of development based on the four dimensions investigated: knowledge about ssis and scientific literacy, the necessity of including ssis in science instruction, situational 
factors related to addressing ssis in class, and teachers' attitude towards teaching ssis.

This research showed that initially the features of ssis were not recognizable to the four Indonesian biology teachers in the study because they had neither experience nor basic knowledge about them before participating and learning about ssis in the teacher professional development program. The content-oriented nature of the Indonesian curriculum drives the culture of teaching, so teachers tend to have less awareness of innovations of instruction, particularly in ssi teaching. However, being introduced to ssi teaching enabled these four teachers to develop basic insights into the importance of ssi teaching practice and to be encouraged to implement ssi teaching in their biology classrooms. Experiencing the implementation of ssi teaching deepened their conceptions about the advantages and challenges of incorporating ssi teaching, from a self-need orientation to improved student achievement and an improvement in the overall classroom environment.

A critical issue that needs to be given consideration for further research is the degree of teachers' concern with respect to their personal values regarding controversial ssis that they may introduce into their teaching practice (Gray \& Bryce, 2006). Although this research did not clearly show the relationship between teaching experience and the teachers' self-reflection, as highlighted by Reis and Galvao (2004) and Albe et al. (2014), a key finding revealed in this research is that the professional learning program on ssi teaching that was employed in this study enabled these teachers to clearly perceive the dimension of ssi teaching in various productive ways. Promoting ssi-based instruction as an innovation in science education has a stronger meaning when it begins with teachers' awareness of their abilities, views, and roles about reform practice.

Concerning the nature of the problems raised in this research, it should be noted that the current research was not intended to examine the degree of successful teacher professional learning about the ssi teaching innovation that was introduced but rather to demonstrate the effectiveness of the teacher development program as a medium to promote such innovation. Moreover, a limitation of this research is that it was conducted using a casestudy design with a limited number of participants, so the findings of this research cannot be generalized. However, considering the research by Pinto (2005), the sustainability of transformation perceived by participants in this research depended on the culture of the educational environment where teachers customized their roles. Further research needs to be carried out in a wider context; in Indonesia it would be especially helpful, for example, to extend the ssi teacher professional development program to different regions, 
to more science teachers, and to further enriching ssi contexts to fulfill curriculum needs.

\section{Acknowledgements}

We express gratitude to the biology teachers who participated in the study and for their great contribution to this research.

\section{Ethical Consideration}

Approval to conduct this study was granted by the Yogyakarta State University Ethics Review Board. The data collected from this project were obtained with the necessary clearance from the partner institutions, guardians, and the students involved in the study. The names of the school and participants used in this study are all pseudonyms.

\section{About the Authors}

Agung W. Subiantoro is a lecturer and researcher in the Department of Biology Education, Yogyakarta State University, Indonesia. He holds a PhD in science education from Curtin University, Australia. His research interest mainly on topics related to socio-scientific issues in biology education, biology education and socio-culture, learners' reasoning skills in science education, and instructional media in biology teaching and learning.

David Treagust is John Curtin Distinguished Professor in the School of Education at Curtin University where he supervises research students on topics related to conceptual change and multiple representations. He holds a PhD and MSc from the University of Iowa, USA, a BSc from the University of Western Australia and a Certificate of Education from Worcester College University of Birmingham, England.

Kok-Sing Tang is an Associate Professor at the School of Education and the discipline lead of the sтем Education Research Group at Curtin University. He holds a BA and MSc in Physics from the University of Cambridge and a $\mathrm{MA}$ and $\mathrm{PhD}$ in Education from the University of Michigan. Kok-Sing is the co-founder and coordinator of a special interest group called 'Languages \& 
Literacies in Science Education' at the European Science Education Research Association (ESERA).

\section{References}

Albe, V., Barrue, C., Bencze, L., Byhring, A.K., Carter, L., Grace, M., Knain, E., Kolsto, D., Reis, P., \& Sperling, E. (2014). Teachers' beliefs, classroom practices and professional development towards socio-scientific issues In C. Bruguiere, et al. (Ed.), Topics and Trends in Current Science Education: 9th ESERA Conference Selected Contributions Springer. https://doi.org/10.1007/978-94-007-7281-6_4.

Anagün, Ş. S., \& Ozden, M. (2010). Teacher candidates' perceptions regarding socioscientific issues and their competencies in using socio-scientific issues in science and technology instruction Procedia - Social and Behavioral Sciences, 9, 981-985. https://doi.org/10.1016/j.sbspro.2010.12.271.

Arroio, A. (2010). Context based learning: A role for cinema in science education Science Education International, 21(3), 131-143. https://files.eric.ed.gov/fulltext/ EJ904864.pdf.

Bakkenes, I., Vermunt, J. D., \& Wubbels, T. (2010). Teacher learning in the context of educational innovation: Learning activities and learning outcomes of experienced teachers Learning and Instruction, 20 533-548. https://doi.org/10.1016/j .learninstruc.2009.09.001.

Barrett, S. E., \& Nieswandt, M. (2010). Teaching about ethics through socioscientific issues in physics and chemistry: Teacher candidates' beliefs Journal of Research in Science Teaching, 47(4), 380-401. https://doi.org/10.1002/tea.20343.

Bitan-Friedlander, N., Dreyfus, A., \& Milgrom, Z. (2004). Types of "teachers in training": the reactions of primary school science teachers when confronted with a task of implementing an innovation. Teaching and Teacher Education (20), 607-619. https://doi.org/10.1016/j.tate.2004.06.007.

Borko, H. (2004). Professional development and teacher learning: Mapping the terrain Educational Researcher, 33(8), 3-15. https://doi.org/10.3102/o013189Xо33008003.

Chowning, J. T., Griswold, J. C., Kovarik, D. N., \& Collins, L. J. (2012). Fostering critical thinking, reasoning, and argumentation skills through bioethics education. PLoS ONE, 7(5), e36791. doi:10.1371/journal.pone.0036791.

Clarke, D., \& Hollingsworth, H. (2002). Elaborating a model of teacher professional growth Teaching and Teacher Education (18), 947-967 https://doi.org/10.1016/So742 $-051 \mathrm{X}(02) 00053^{-7}$.

Creswell, J. W., \& Miller, D. L. (2000). Determining validity in qualitative inquiry. Theory Into Practice, 39(3), 124-130. https://doi.org/10.1207/s15430421tip39o3_2. 
Davis, K. S. (2003). "Change is hard": What science teachers are telling us about reform and teacher learning of innovative practices Science Education, 87(1), 3-30. https:// doi.org/10.1002/sce.10037.

Dawson, V. M., \& Venville, G. J. (2013). Introducing high school biology students to argumentation about socioscientific issues Canadian Journal of Science, Mathematics and Technology Education 13(4), 356-372 https://doi.org/10.108o/14926156.2013 .845322 .

Ekborg, M., Ottander, C., Silfver, E., \& Simon, S. (2013). Teachers' experience of working with socio-scientific issues: A large scale and in depth study. Research in Science Education, 43(2), 599-617. https://doi.org/10.1007/s11165-011-9279-5.

Feierabend, T., \& Eilks, I. (2010). Raising students' perception of the relevance of science teaching and promoting communication and evaluation capabilities using authentic and controversial socio-scientific issues in the framework of climate change. Science Education International, 21(3), 176-196 https://files.eric.ed.gov/full text/EJ904867.pdf.

Forbes, C. T., \& Davis, E. A. (2008). Exploring preservice elementary teachers' critique and adaptation of science curriculum materials in respect to socioscientific issues Science \& Education, 17, 829-854. https://doi.org/10.1007/s11191-007-9o8o-z.

Gray, D. S., \& Bryce, T. (2006). Socio-scientific issues in science education: Implications for the professional development of teachers. Cambridge Journal of Education, 36(2), 171-192. https://doi.org/10.108o/030576406oo718489.

Guskey, T. R. (2002). Professional development and teacher change. Teachers and Teaching: theory and practice, 8(3), 381-391. https://doi.org/10.1080/1354060021 ooooo512.

Henze, I., van Driel, J. H., \& Verloop, N. (2009). Experienced science teachers' learning in the context of educational innovation Journal of Teacher Education, 6o(2), 184-199. http://doi.org/10.1177/oo22487108329275.

Herlanti, Y., Rustaman, N., Rohman, I., \& Fitriani, A. (2012). Kualitas argumentasi pada diskusi isu sosiosaintifik mikrobiologi melalui weblog. (The argumentation quality of socio-scientific issues on microbiology topic via weblog). Jurnal Pendidikan IPA Indonesia, 1(2), 168-177. https://doi.org/10.15294/jpii.vii2.2135.

Hofstein, A., Eilks, I., \& Bybee, R. (2011). Societal issues and their importance for contemporary science education - A pedagogical justification and the state-of-the-art in Israel, Germany, and the USA. International Journal of Science and Mathematics Education (9), 1459-1483. https://doi.org/10.1007/s10763-010-9273-9.

Holbrook, Jack., \& Rannikmae, M. (2009). The meaning of scientific literacy. International Journal of Environmental \& Science Education, 4(3), 275-288. https:// files.eric.ed.gov/fulltext/EJ884397.pdf.

Kara, Y. (2012). Pre-service biology teachers' perceptions on the instruction of socioscientific issues in the curriculum. European Journal of Teacher Education, 35(1), 111-129. https://doi.org/10.108o/o2619768.2011.633999. 
Kilinc, A., Afacan, O., Polat, D., Guler, P.D., Yildimit, K., Demiral, U., Eroglu, B., Kartal, T., Sonmez, A., Iseri, B., Gorgulu, O. (2014). Preservice science teachers' beliefs system about teaching a socioscientific issue. Journal of Turkish Science Education, 11(3), 79-102. https://doi.org/10.12973/tused.10120a.

Konings, K. D., Brand-Gruwel, S., \& van Merrienboer, J. J. G. (2007). Teachers' perspectives on innovations: Implications for educational design Teaching and Teacher Education, 23, 985-997. https://doi.org/10.1016/j.tate.2006.o6.oo4.

Lee, H., Abd-El-Khalick, F., \& Choi, K. (2006). Korean science teachers' perceptions of the introduction of socio-scientific issues into the science curriculum. Canadian Journal of Science, Mathematics and Technology Education, 6(2), 97-117. https://doi .org/10.1080/149261506o9556691.

Lee, H., \& Witz, K. G. (2009). Science teachers' inspiration for teaching socio-scientific issues: Disconnection with reform efforts. InternationalJournal of Science Education, 37(7), 931-96o. https://doi.org/10.1080/o950o69o8018989o3.

Lenz, L., \& Willcox, M. K. (2012). Issue-oriented science: Using socioscientific issues to engage biology students The American Biology Teacher 74(8), 551-556.

Merriam, S. B. (1990). Case Study Research in Education, A Qualitative Approach: Jossey-Bass Publisher.

Miles, M. B., \& Huberman, A. M. (1994). Qualitative Data Analysis SAGE Publications.

Nida, S., Mustikasari, V.R., \& Eilks, I. (2020). Indonesian pre-service science teachers' views on socio-scientific issues-based science learning. Eurasia Journal of Mathematics, Science and Technology Education, 17(1), em1932, https://doi.org/10 $.29333 /$ ejmste/9573.

Nida, S., Rahayu, S., \& Eilks, I. (2020). A survey of Indonesian science teachers' experience and perceptions toward socio-scientific issues-based science education. Education Sciences, 10(2), 39, https://doi.org.10.3390/edusci10o20039.

Ottander, C., \& Ekborg, M. (2012). Students' experience of working with socioscientific issues - a quantitative study in secondary school. Research in Science Education, 42(6), 1147-1163. doi:10.1007/s11165-011-9238-1.

Peers, C. E., Diezmann, C. M., \& Watters, J. J. (2003). Supports and concerns for teacher professional growth during the implementation of a science curriculum innovation Research in Science Education (33), 89-110. https://doi.org/10.1023/A:1023685113218.

Pinto, R. (2005). Introducing curriculum innovation in science: Identifying teachers' transformations and the design of related teacher education Science Education, 89 (1), 1-12. https://doi.org/10.1002/sce.20039.

Reis, P., \& Galvao, C. (2004). The impact of socio-scientific controversies in Portuguese natural science teachers' conceptions and practices Research in Science Education, 34, 153-171. https://doi.org/10.1023/B:RISE.0oooo3376o.04656.a1.

Sadler, T. D. (2011). Situating socio-scientific issues in classrooms as a means of achieving goals of science education In T. D. Sadler (Ed.), Socio-scientific Issues in the Classroom: Teaching, Learning and Research (pp. 1-9). Springer. 
Sadler, T. D., \& Dawson, V. (2012). Socio-scientific issues in science education: Contexts for the promotion of key learning outcomes In B. J. Fraser, K. G. Tobin, \& C. J. McRobbie (Eds.), Second International Handbook of Science Education (pp. 7998o9). London: Springer International Handbooks of Education.

Simon, S., \& Campbell, S. (2012). Teacher learning and professional development in science education In B. J. Fraser, K. G. Tobin, \& C. J. McRobbie (Eds.), Second International Handbook of Science Education Springer.

Subiantoro, A. W. (2017). Promoting socio-scientific issues-based learning in biology: Indonesian students' and teachers' perceptions and students' informal reasoning. Unpublished Doctoral thesis, Curtin University, Australia. Accessed from https:// pdfs.semanticscholar.org/1731/6e1c58cb58ea7929ebfoa37a257166bao1bd.pdf.

Tal, T., \& Kedmi, Y. (2006). Teaching socioscientific issues: Classroom culture and students' performances Cultural Studies of Science Education, 1, 615-644. https://doi .org/10.1007/s11422-006-9026-9.

van den Akker, J. (1988). The teacher as learner in curriculum implementation Journal of Curriculum Studies, 20(1), 47-55. https://doi.org/10.1080/0022027880200104.

Wolfensberger, B., Piniel, J., Canella, C., \& Kyburz-Graber, R. (2010). The challenge of involvement in reflective teaching: Three case studies from a teacher education project on conducting classroom discussions on socio-scientific issues. Teaching and Teacher Education: An International Journal of Research and Studies, 26(3), 714721. https://doi.org/10.1016/j.tate.2009.10.007.

Yin, R. K. (1994). Case study research; Design and methods. Sage Publication.

Zeidler, D. L., Sadler, T. D., Simmons, M. L., \& Howes, E. V. (2005). Beyond STS: A research-based framework for socioscientific issues education. Science education, 89(3), 357-377. doi:10.1002/sce.20048.

Zeidler, D., \& Nichols, B. (2009). Socioscientific issues: Theory and practice. Journal of Elementary Science Education, 21(2), 49-58. https://doi.org/10.1007/BFo3173684.

Zeidler, D. L. (2013). Socioscientific issues as a socio-cultural approach to scientific literacy Paper presented at the East-Asian Association for Science Education International Conference, 4-6 July 2013, The Hong Kong Institute of Education, Hong Kong, China.

Zeidler, D. L., Herman, B. C., Ruzek, M., Linder, A., \& Lin, S.-S. (2013). Cross-cultural epistemological orientations to socioscientific issues Journal of Research in Science Teaching, 5o(3), 251-283. https://doi.org/10.1002/tea.21077. 